\title{
Will Virtual Replace Classroom Teaching? Lessons from Virtual Classes via Zoom in the Times of COVID-19
}

Dr. Murillo de Oliveira Dias", Dr. Raphael de Oliveira Albergarias Lopes, Andre Correia Teles

Fundação Getulio Vargas, Brazil

\author{
DOI: $10.36348 /$ jaep.2020.v04i05.004 \\ | Received: 07.05.2020 | Accepted: 15.05.2020 | Published: 19.05.2020 \\ *Corresponding author: Murillo de Oliveira Dias
}

\section{Abstract}

Two months after the World Health Organization (WHO) has declared the COVID-19 as a pandemic, near 3.7 million people were confirmed positive to the coronavirus, with 253.831 deaths. While Mankind fights desperately for survival in a critical moment in human history, most teachers had to reinvent themselves in a joint effort to avoid a complete halt in educational activities; suspended sine die around the globe. This article investigated the challenges faced by teachers, and executive education professors in Brazil, through live online classes via the Zoom platform. Key findings pointed out (i) the lack of stable online connection; (ii) security issues; (iii) limited pedagogical resources; (iv) background noises; (v) shortage of equipment supply due to the lockdowns, as barriers to online live classes dispensed with the Zoom platform. This study aims at providing scholars, teachers, professors, instructors, practitioners, online service providers, software developers, among others, with a perspective regarding the online live education experience. We also compared live virtual with classroom teaching, promoting the debate on the implications and best practices.

Keywords: COVID-19, education, pandemic, virtual, classroom, teaching.

Copyright @ 2020: This is an open-access article distributed under the terms of the Creative Commons Attribution license which permits unrestricted use, distribution, and reproduction in any medium for non-commercial use (NonCommercial, or CC-BY-NC) provided the original author and sources are credited.

\section{INTRODUCTION}

COVID-19 is the disease caused by the SARS-CoV-2 virus [1], which first appeared at the Chinese province of Wuhan in November 2019, quickly spreading overseas. On 11 March 2020, the World Health Organization (WHO) declared the COVID-19 pandemic [1]. Since then, human history is being rewritten. Humanity faced the collapse of medical services, had to adapt overnight to lockdowns, quarantines, social isolation, house confinement, home office, unemployment rates, shortages, suspension of sports activities - including the Tokyo Olympics 2020 (rescheduled for 2021) to name a few, with an uncertain date for the activities to return. Rapidly, panic and fear contagion spread, intensified by social and mass media, who played their part in shaping fears of the coronavirus disease [2].

Virtually all governments took actions for the prevention and containment of the COVID-19: the national emergency was declared in many countries (including Brazil); international flights canceled; frontiers closed; transportation across the country controlled; schools, universities, shopping centers, touristic points, retail business, all but essential businesses (pharmacies, groceries, and supermarkets in general) were closed, public activities suspended. As an extreme measure to combat the coronavirus, the Indian government observed a 14-hour curfew [3]. On 13 March 2020, Brazilian government suspended all classes in Brazil.

Lockdown was declared on 17 March in the principal Brazilian cities. Currently, all the 27 states have cases of contamination with the COVID-19 recorded. While this article is written, 128,000 cases and 8,609 deaths were registered in approximately two months. The Brazilian medical service collapsed in many regions [4].

Since March 2020, educational institutions teachers, professors, trainers, instructors, after an initial shock and panic, gradually joined efforts to devise ways to avoid a complete stop in classes all over the country, also to find creative ways to engage students online. Many Brazilian institutions substituted classroom teaching temporarily by live streaming technology. For instance, videoconferences and online chat services through cloud-based peer-to-peer software platforms, such as Skype, Google Duo, 
WhatsApp, Hangouts, and Zoom ${ }^{1}$, with respective limitations, were adopted.

This multiple case study investigated the virtual live classes dispensed through Zoom platform, to $\mathrm{N}=66$ students distributed in two Brazilian MBA courses, as the unit of analysis [5], between April-May 2020. Multiple qualitative methods were employed to achieve the results. Then, we followed past research on the subject, which attracted scholar attention recently [1-6].

Real and virtual synchronous classes were compared, aiming at providing scholars, professors, teachers, instructors, with a new perspective on the pros and cons of the virtual classes via Zoom, sharing experiences helpful to the academic community, and ultimately discussing the future of the classroom teaching.

Negotiation and Conflict management course was chosen for investigation because negotiation courses are eminently attended in person, once the negotiation is a social interaction process, involving people and the substance negotiated [7]. Teaching negotiation remotely, thus, presented additional challenges, once many group dynamics simply could not be taught remotely, for instance, the two-participant arm-wrestling dynamic, among others.

Finally, will virtual replace classroom teaching? We answer this puzzling question in the next sections.

\section{RESEARCH METHODOLOGY}

This study used a qualitative research approach, interpretive, inductive reasoning, combining multiple methods, such as (i) multiple case study [4], (ii) qualitative interviews, (iii) direct participation, and (v) direct observation.

Two MBA classes were investigated, within two different regions: Porto Alegre, capital from the Rio Grande do Sul state, southern region ( $n=32$ students), Goiânia, capital from Goiás, center-west region ( $n=34$ students), totaling $\mathrm{N}=66$ students, on the same course: Negotiation and Conflict Management, from 13 April to 5 May 2020 through six live classes. Out of the $N=66$ students, 60 percent are male, 40 percent female; average age 25-35 years old; 90 percent employed; 80 percent Caucasian. The professors, however, live in Rio de Janeiro, an average $1,000 \mathrm{~km}$ away from the localities where the courses should be dispensed in real classes through the Zoom platform.

\footnotetext{
${ }^{1}$ Zoom communications software is featured by the Zoom Video Communications, Inc., which is a North American communications technology company headquartered in San Jose, California, founded in 2011.
}

Interviews $(n=5)$ were conducted between classes, through a semi-structured questionnaire, with a 100 percent response rate. In 100 percent of the cases, the participants were invited and interviewed remotely through WhatsApp. The quotation was allowed, but the identities were preserved, to avoid compliance issues by request.

The primary raw data were coded through descriptive and In Vivo codes 8], following Goffman's drama theory $[9,10]$. This study is limited to the Brazilian Fundação Getulio Vargas (after that Educational Institution - E.I.) 432-h MBAs, 24hmodules. The research is also limited to the Negotiation and Conflict Management module. Other countries, educational institutions, courses, and modules should be investigated separately. The primary raw data was then coded through descriptive and In Vivo codes 8], following Goffman's drama theory [9]-[10].

This study is limited to the Brazilian Fundação Getulio Vargas (thereafter Educational Institution - EI) 432-h MBAs, 24h-modules. The research is also limited to the Negotiation and Conflict Management module. Other countries, educational institutions, courses, and modules should be investigated in separate.

\section{Quarantine declared: cancellations and first response}

On 19 March 2020, the EI canceled all the remaining classes between 17 to 29 March, postponing them to future dates to be rescheduled.

Then, on 23 March, one week after the beginning of the quarantine, the E.I. presented the following contingency plan, designed to avoid the complete halt of the classes: (i) the remaining exams from the classes, which courses had already been dispensed, were substituted by individual online assignments; (ii) real classes would be substituted temporarily by virtual ones; (iii) the new classes should be dispensed through Zoom cloud communication platform; (iv) three waves of Zoom pieces of training would be dispensed to prepare the professors, according to the proximity of the classes, case by case; (v) the courses activities should be resumed from 1 April 2020 until the end of the quarantine; (vi) virtual classes should follow the same timetable as in-person classes.

In practical terms, once the authors' first class within the quarantine would be dispensed on 13 April 2020 , the professors had approximately 30 days to (i) adapt the courses to the new class format, i.e., from real to virtual classes; (ii) to become a "Zoom expert" as soon as possible.

The Zoom platform was chosen because of the number of the participants allowed per meeting: while WhatsApp allows four participants per meeting, Zoom may support $+1,000$ participants per meeting. The E.I. 
contracted, however, the Zoom unlimited time for meetings, up to 300 participants' meetings. (Zoom standard is 40 minutes free, 100 participants max). Usually, MBA classes are dispensed in four modules of five hours each, plus the four hours of exam elaboration and corrections, totaling 24 hours, each module. Usually, the classes are dispensed from 8:00 AM to 5:40 PM, depending on the local class arrangement with the E.I.

The Zoom training took place on 24 March 2020, one day after the EI issuing the contingency plan. How to prepare the classes to dispensed in the new format?

\section{Uncertainty, zoom training and classes preparation}

The basic two-hour Zoom training introduced the main commands and features. The interface was intuitive and friendly, available in Brazilian Portuguese. We use to teach with Microsoft PowerPoint slides, with movies embedded in the presentations, with audio.

The Zoom shares a screen with the audience, both video with audio, but through a manual command (the function is not automatic).

We use to teach with Microsoft PowerPoint slides, with movies embedded in the presentations, with audio. The Zoom shares a screen with the audience, both video with audio, but through a manual command (the function is not automatic).

First, all group dynamics in the classroom had to be removed, given the lack of students physically present in the classroom. The idea was to substitute group dynamics by role-playing simulations, with emphasis on extensive negotiation mapping and preparation. The analytical tools for negotiation preparation and further analysis proved useful at the end of the day. The students had to submit their maps after the negotiation debriefing, after comparing preparation with the case execution.

The E.I. established on 26 March 2020 that the presence in virtual classes was not required. In other words, a student could be approved in a given course without taking classes, only by approval on the individual assignment deliverance. How to persuade the students to take the classes?

The solution came with the percent grade distribution: the E.I. allows 30 percent of the final grade to be composed of classroom participation. Therefore, the students were told that maximum grades would be available only for students who performed all the four role-play simulations. Simply put, a student would not be entitled to the maximum grade if he did not participate in all activities, including the online class.
The strategy proved useful because 100 percent of the $\mathrm{N}=66$ students attended the classes $\left[{ }^{2}\right]$.

Then, the negotiation role-play simulations are composed of confidential instructions. Immediately three crucial questions had to be addressed: (i) how to avoid one participation reading the opponent's instructions? (ii) How to avoid sending one by one a file with the respective parties assigned correctly? In a class with 32 students, it would represent sending 32 files to 32 students, 16 part one files, and 16 part 2 files, after the matchmaking, extremely time-consuming. Finally, (iii) how to integrate visiting students from other cohorts (students fulfilling modules)?

The Zoom's breakout rooms proved ineffective because all the parties' instructions should be dispensed in parallel. For instance, in a class of 32 students, 16 breaking rooms should be formed. However, the professor could not prevent sending 16 times part 1 and 16 times the part 2, individually. How to solve this puzzle?

We created WhatsApp groups. The students were required previously to form two groups (groups one and two). For each group, the professor should send only one file per group (part 1 sent one time to the entire group 1, and part 2 sent one time to the entire group 2). This way, instead of sending the same file 16 times, only one time should be enough. Each student from group one would pick another student from group two, to match a pair. The professor should allocate the visiting students to any of the two groups. It worked perfectly well. Figure 1 illustrated the groups' division:

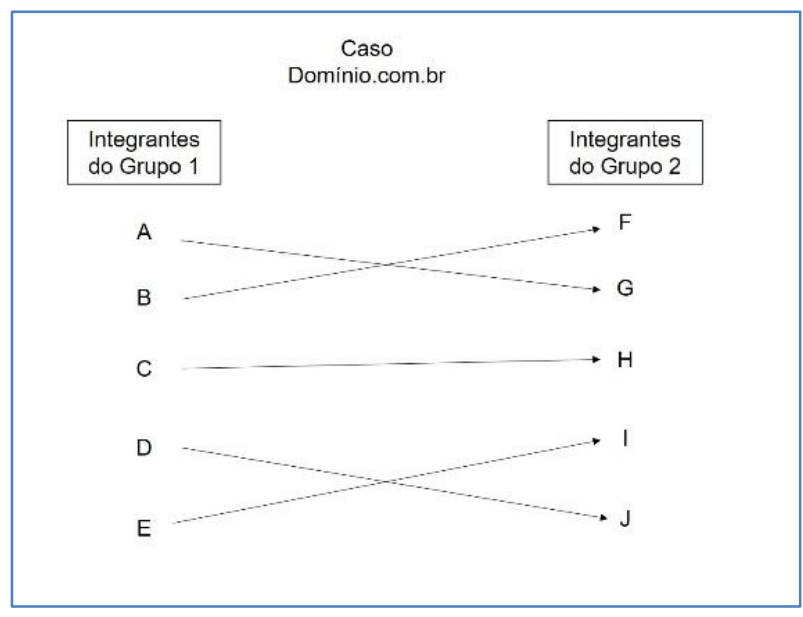

Fig-1: Role-play simulation parties pair matching.

If the parts distribution had to be performed manually, the same $n=32$ students $x 4$ cases $=128$ files

\footnotetext{
2 In Brazil, the minimum grade to pass is $7 / 10$, according to the Ministry of Education. Therefore, if the student does not participate in the virtual classes, the maximum grade possible would be 7/10. Too risky. Therefore, all the students engaged in the virtual classes, with this "little incentive."
} 
sent per module. If each file takes $30 \mathrm{~s}$ to be sent, $128 \mathrm{x}$ $30=3,840$ s to complete the task, or 64 minutes spent, nearly one hour spent only with case distribution.

The students chose their counterparts in the other group, read their parts, planned the negotiation in a map built for this purpose, and then engaged in the negotiation. After the debriefing session, the case was over.

The final issue regarded the virtual class structure and timing: how long the students would endure for theoretic contents exposure? By experience, not more than 45 minutes. Therefore, the course was structured as follows: $45 \mathrm{~min}$ of content exposure, 15minute break, two-hour role-play simulation, one-hour debriefing, and wrap up sessions. It worked perfectly fine. The course was restructured: it just needed to be put into practice.

\section{First Classes with Zoom}

High levels of anxiety marked the first day of classes via Zoom. The first session included $n=32$ students, the professor, plus the course coordinator, one professor monitor, and one faculty member, to act as facilitators. In practice, more pressure than regular classes.

Fortunately, the planning went well. "It was quite an interesting experience" (Ineterviewee\#1). "I thought that you had previous experience with Zoom" (Interviewee\#2).

The degree of interaction with the professor is much lower in the virtual class than in the classroom. Some leave the microphone and camera off. Some leave the microphone on, capturing unpleasant noises. On the first day of classes, taught from 6 PM to 11 PM, one of the relatives of a given student complained with the student aloud. Children caused distractions in some occasions. Once the participants attend the classes mostly from home, due to the quarantine, such distractions are almost inevitable.

On the third session out of four, the internet connection remained unstable: "The connection is horrible" (Interviewee\#1), "I cannot hear what he says" (Interviewee\#3), "I do not have patience" (Interviewee\#4) was the most frequent commentaries. Finally, the Zoom meeting was interrupted five times in twenty minutes. The content exposition had to be stopped, and the exercise substituted the theoretical explanations.

In general, the exercises took 30 to 40 minutes to average longer than in the classroom. The outcomes were 20 percent lower than in the classroom. With more time consumed with each task, a lesser number of tasks could be applied within the same period of classes in the classroom. In sum, the same course includes five role-play simulations negotiations, plus five group dynamics, totaling ten practical exercises. In the virtual classes via Zoom, only the five role-play simulations could be applied. Figure 2 illustrates the differences between classroom and virtual classes:

\begin{tabular}{|lll|}
\hline Feature & Virtual & Classroom \\
\hline noise & background noise & conversation noise \\
parents interruption & yes & - \\
pedagogical resources & limited & unlimited \\
group dynamics & - & five \\
role-play simulation & five & five \\
Preparation mapping & yes & yes \\
connection stability & crucial & - \\
security online issues & crucial & - \\
video recording & allowed & - \\
cloud storing & allowed & - \\
theoretical content & full & full \\
communication channel & intermittent & continuous \\
\hline
\end{tabular}

Fig-2: Comparison of virtual vs. classroom classes

Notice in Figure 2 the differences between virtual and classroom teaching. Observe the barriers to online live classes dispensed with Zoom, summarized as follows: (i) the lack of stable online connection; (ii) security issues; (iii) limited pedagogical resources; (iv) background noises; finally, an additional barrier, the (v) shortage of equipment supply due to the lockdowns.

\section{ANALYSIS AND DISCUSSION}

The most significant advantages from Virtual classes via Zoom over the classroom teaching are the video recording, cloud storing, and sharing, for a limited time (30 days). Virtual classes can also be downloaded and stored in the hard drive. However, the disadvantages exceed the advantages, when compared to classroom interactions.

First, the virtual classes are highly dependent on the internet connection at the moment in which the virtual classes are dispensed, for both professors and students. The absence of

Then, the Zoom Company jumped from 10 to 100 million subscribers in one month. Security breaches have been reported.

The real, touchable place to learn and teach, is the classroom. The same environment cannot be properly reproduced in the virtual classes via zoom or any other communication software. Also, in virtual classes, it is easier for the student to avoid direct participation and engagement. The interactions in the classroom are superior in quality and quantity in comparison to virtual classes. 
Also, the absence of face-to-face contact in virtual negotiations leads students to miss the subtleties and important visual cues of the non-verbal language.

Next, the analysis indicated that the student-tostudent interactions were less effective in the virtual classes than in classroom ones, because the students are apart from each other.

Later, findings indicated that the interactions between professor-to-student and vice versa are less detailed within the virtual classes than in classroom ones.

Ultimately, answering the research question, we found evidence that the virtual classes will not replace the classroom teaching after the COVID-19 pandemic is over.

\section{Implications}

The case has direct implications in several fields of research, not limited to (i) health care services [11]; (ii) overall waterway touristic services [12]; (iii) air cargo transportation [13-14]; (iv) aerospace industry [15-23]; (v) airport network [16-18], (vi) teaching materials in negotiations [19-22] (vii) craft beer industry [24-25], among others.

First, the quarantined confinement and social isolation affected the human psyche directly in several ways, causing distress, higher levels of anxiety, depression, among others. Therefore, the end of the pandemic implies the return to normality. Moreover, classroom teaching represents the liberty of dreadful confinement.

Second, the online communication experience should be improved on security issues, stability connection, and higher quality rates on video and audio transmission, to name a few improvements.

Third, not all students accepted to take virtual classes. Some simply decided not to engage in virtual classes, preferring to wait for the final of the pandemic.

Finally, the practical teaching activities will increase, in direct proportion to technological upgrades that could solve the current lack of broadcast quality, security issues, for instance. Virtual classes will not eradicate classroom teaching, especially within courses in which group dynamics are of utmost essential to the learning process. After the COVID-19 pandemic is over, the relationship with the classroom will be different: students will use masks in all classes. The preoccupation with hygienic issues will be intensified; kisses and other forms of social contact tend to be modified. Simple pleasures of life will gain an unexpected proportion, like friendship and family life; people will feel free and happy to be healthy, even more than before the pandemic. Those who survive at the time will see.

\section{Future research}

Future research is encouraged to assess the impact of the virtual classes in the professional career of the students. Are the virtual classes useful, like the classroom ones? Studies are also encouraged to investigate the students' engagement in virtual classes.

\section{REFERENCES}

1. Dias, M., Lopes, R. (2020). Will the COVID-19 Pandemic Reshape our Society? EAS Journal of Humanities and Cultural Studies, 2(2), 93-97.

2. Times (2020). How Social Media Is Shaping Our Fears of - and Response to - the Coronavirus. Retrieved from https://time.com/5802802/socialmedia-coronavirus/, on 7 May 2020.

3. BBC (2020). Coronavirus: India observes 14-hour curfew. Retrieved from https://www.bbc.com/news/world-asiaindia51992364 on 7 May 2020.

4. Ministério da Saúde. (2020). Painel Coronavirus. Retrieved from https://covid.saude.gov.br/, on 7 May 2020.

5. Yin, R. (1988). Case Study Research: Design and Methods. Newbury Park, CA: Sage Publications.

6. Cruz, B.S.; Dias, M. (2020). COVID-19: from Outbreak to Pandemic. Global Scientific Journals, 8(3), 2230-2238. doi: 10.11216/gsj.2020.03.37636

7. Dias, M. (2019). People, Process, and Substance: Current Definitions on Negotiation. International Journal of Commerce and Economics, 1(3), 1-9. doi: 10.13140/RG.2.2.15836.95360

8. Saldaña, J. (2013). The coding manual for qualitative researchers. Thousand Oaks, CA: SAGE Publications.

9. Goffman, E. (1959). The Presentation of Self in Everyday Life. New York: Doubleday.

10. Goffman, E. (1961). Encounters: Two Studies in the sociology of interaction. Indianapolis: The BobbsMerrill Company.

11. Craveiro, M., Dias, M. (2019). Case on Brazilian Health Care Unit on Pulmonary Tuberculosis. Global Scientific Journals, 7(12), 613-625.

12. Dias, M., Lopes, R. (2020) Case on Cruise Ship Failure Services: Onboard. Kuwait Chapter of the Arabian Journal of Business and Management Review, 9(1), 10-19.

13. Dias, M., Lopes, R. (2020). Air Cargo Transportation in Brazil. Global Scientific Journals, 8(2), 4180-4190.

14. Dias, M. (2020). Air Transportation in Brazil: São Paulo Congonhas Airport. Global Scientific Journal, 8(2), pp. 3244-3252

15. Cruz, B., Dias, M. (2020). Crashed Boeing 737MAX: Fatalities or Malpractice? Global Scientific Journal, 8(1), pp. 2615-2624. 
Murillo de Oliveira Dias et al; J Adv Educ Philos, May., 2020; 4(5): 208-213

16. Dias, M. (2019). Santos Dumont Airport: Civil Aviation in Rio de Janeiro, Brazil. Saudi Journal of Engineering and Technology, 4(10), 418-421.

17. Dias, M. (2019). Air Passenger Transportation in Brazil. Global Scientific Journal, 7(10), pp. 310317.

18. Dias, M. (2019). Air transportation in Brazil: Guarulhos International Airport. South Asian Research Journal of Business and Management, 1(4), 182-187.

19. Dias, M. (2019). Is it Worth Competing at the Bargaining Table? Global Scientific Journals, 7(9), 1-14. doi: 10.13140/RG.2.2.11557.45288
20. Dias, M., \& Lopes, R. (2019). Role Play Simulation on Farm Debt: Brazilian Case. International Journal of Humanities and Social Science, 6(4), 84-93.

21. De Oliveira Dias, M., \& Falconi, D. (2018). The Evolution of Craft Beer Industry in Brazil. Journal of Economics and Business, 1(4), 618-626.

22. Dias, M. (2018). Heineken Brewing Industry in Brazil. International Journal of Management, Technology and Engineering, 8(9), 1304-1310. doi:16.10089/IJMTE2156 